الوظائف الاينية للأحناف في مصر في العصر المملوكي

(1517-1250 / 923 -648)

محمد محمد مغاوري محمد*

$$
\text { إشراف }
$$

د.صفى على محمد***

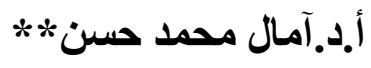
د.شيرين شلبى العثماوي ****

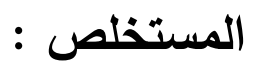

يهدف هذا البحث إلى رصــ الوظائف الدينية التي تولاها الأحناف في مصـر في عصـر سـلاطين المماليك، وهو ما يبرز المكانة التي وصـلوا إليها، ويكثـف عن الدور الذي لعبوه في مصـر خلال العصـر المملوكي، كما يعكس صورة النشاط المذهبي في ذلك العصر .

تتاول البحث وظائف الأحناف الدينية في الدولة المملوكية بمصـر والتى كان أهمها القضــاء، حيث سيطر القضـاة الأحناف على كثثر من مفاصل الدولة المملوكية، وقد تتوعت طرق اختيار قاضـي قضـاتهم، فتمت عن طريق العلاقات الودية مع الســـلاطين أحيانًا، وبرغبة الأحناف حينا، وعن طريق البذل والبرطلة أحيانا أخرى.

ولم تقتصر تلك الوظائف على القضـاء بل شملت الحسبة، كما باشر بعضهم نظارة بعض الأعمال في الدولة كالجوالي والأحباس والكسوة.

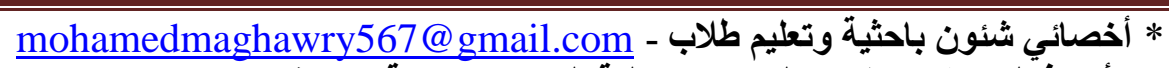

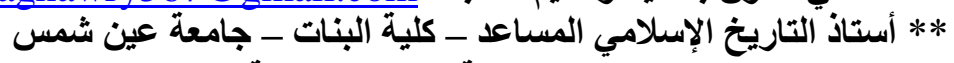

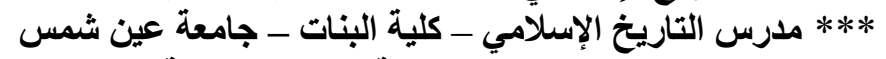

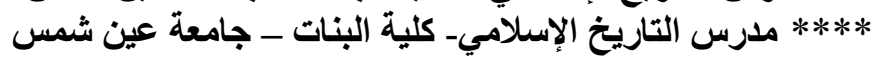


يعد العصر المملوكي (648- 923هـــ250-123 1517م) من أهم العصـور التي شهـت نشـاطا متزايدا لأصحاب المذاهب الفقهية المختلفة ومن بينها المذهب الحنفي الذي انتشر في مصر انتشارًا واسعًا في عصر سـلاطين المماليك، فتمذهب به السـلاطين والأمراء والعامة، ووصـل الأحناف، أمراء وقضـاة وفقهاء، إلى مكانة مرموقة في الدولة المملوكية، وحظوا برعاية السـاطين والأمراء المماليك، ونتيجة لتلك المكانة تولوا العديد من الوظائف الدينية المهمة في الدولة، كالقضـاء، والحسبة، وقضـاء العسكر ، ونظارة بعض الدواوين، وغير ذللك من الوظائف.

يهـدف هذا البحث إلى رصــ الوظائف الدينية التي نولاها الأحناف في مصـر في عصـر سـلاطين المماليك، لما لذلك من أثر في إبراز المكانة التي وصـل إليها الأحناف، والدور الذي لعبوه في مصـر خلال عصر المماليك، وأن يعكس صورة النشاط المذهبي في ذلك العصر .

أما عن منهج الدراسـة فقد اعتمد البحث على المنهج الاستقرائي الذي يقوم على اسـتقراء النصـوص وتحليل مضمونها للوصول إلى الحقائق التاريخية والتعرف على الوظائف الدينية التي تولاها الأحناف بمصر لهر

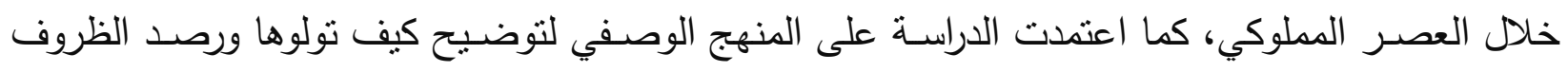
والحوادث التي مكنتهم من احتلال نلاك المكانة في مصر . استلزم إعداد هذا البحث الرجوع إلى عدد من الإراسـات السـابقة وإن كانت قد اقتصرت على دراسـة للقضاة والفقهاء بشكل عام دون تحديد مذهب فقهي معين. اعتمد الباحث على دراسة خالد الحريري: "قاضي القضاة ودوره في دولة المماليك البحرية" مما سهل عقد المقارنات بين القضـاة الأحناف وبين غيرهم من القضــاة، والدراســة التى قدمها الاســاذ الدكتور حسـن البطاوي: "أهل العمامة في مصر عصر سـلاطين المماليك" حيث استعرض من خلالها الأدوار التي قام بها 
فقهاء مصر بشكل عام في العصر المملوكي، والدراسة التي قدمتها الأستاذة الدكتورة سهام أبو زيد: "الحسبة في مصـر الإسـلامية"، والدراسـة التي قدمها الدكتور طلعت عكاثــة "الفتاوى الدينية في مصـر والثنـام في العصر المملوكي" ومن خلالها أمكن التعرف على أسباب إصدار تلاك الفتاوى وما كان يترتب عليها. وقد جاءت خطة الدراسة ، مقسمة إلى مقدة وخاتمة وثلاثة مباحث على النحو التالي: المبحث الأول: مكانة الأحناف في الدولة المملوكية. المبحث الثاني: القضاة والمفتون الأحناف المبحث الثالث: المحتسبون والنظار.

أولا : مكانة الأحناف في الدولة المملوكية

علت مكانة الأحناف في مصـر في العصـر المملوكي بعد انتشـار مذهبهم بين السـلاطين والأمراء والأعيان والعامـة، حتى أن الســلطلان بييرس (ابن تغري بردي، 1992:ص109)، حين رتب للمذاهب في مصر قضاة للقضاء سنة 663هـ/264م جعل للحنفية قاضيا ورتب له نوابًا (ابن دقماق، 1982 :ص275)، وكان أبو الربيع سليمان (ت677هـــ/ 1278م)أول قاض لقضـاة الحنفية بالديار المصرية، وبعدها أصبح الأحناف، ممتلين في قاضي قضاتهم، يحضرون مجالس الثورى مع السلطان والخليفة العباسي وغيرهم من قضـاة المذاهب الأخرى(عثمان عطا،2008 : ص271)، كما كانت العادة إذا جلس السـلطان في دار العدل بالقلعة للنظر في المظالم أن يجلس قضاة المذاهب الأربعة عن يمينه، وكان القاضي الثـافعي هو الذي يلي الســلطـان وإلى جانبه القاضـــي الحنفي(ابن حجر، 1993 ص438، 440)، بل إن الأمير الحنفي يلبغا الخاصكي حاول أن يُجلس القاضي الحنفي قبل الثافعي، إلا أن ذلك لم يتم، فظل ترتيب جلوس القضاة كما كان إلى أن استقر ترتيب جلوسهم في أواخر العصر المملوكي على أن يجلس السطان بين قضـاة المذاهب 
الأربعة وعن يمينه القاضــي الثــافعي ثم المالكي، وعن يســاره الحنفي ثم الحنبلي (القلقتــندي، 1922: ص35).

كان ارتباط قضــــاة الحنفية ببعض الأمراء عاملا مهما في حصــــولهم على كثير من الامتيازات، نموذج ذلك: قاضي قضـاة الحنفية سراج الدين الهندي(ت 773هـــ1371م)(ابن حجر،1988: ص288) الذي احتقظ بعلاقات قوية مع بعض أمراء المماليك ، الذين ساعدوه كثبرًا في الحصول على عدة مزايا، منها: استصدار مرسوم سلطاني بأن يلبس الطرحة في المواكب ويستتبب عنه قضاة في أعمال مصر من شمالها إلى جنوبها، ويفرد له مودع لأموال يتامى الحنفية، كما يفعل قاضي قضـاة الثنافعية(محمد دهمان، 1990 : ص107) كما نقرر الأمر نفسه مع قاضي قضاة الحنفية جلال الدين جار الله (ت782هـ/ 1380م) بمساعدة أحد الأمراء، حتى شق ذلك على قاضي قضاة الثنافعية وسعى في إبطاله (السيوطي،1967:ص 184).

أولى ســاطين المماليك وأمراؤهم رعايتهم واهتمامهم للأحنافَ في مصـر ، وظلت تلاكك الرعاية ممتدة

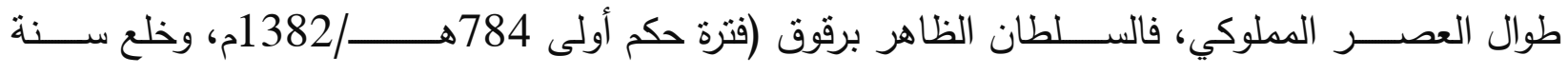
791هـ/1388م)(فترة حكم ثانية 801هـ/1399م) (الثوكاني، 1993:صـ162-163) كان معظمًا للثيخ شـرف الدين التباني (السخاوي، 1988 : ص 282- 283)، فلم يكن يرد أي طلب له، وبالمتل كان للثـيخ نظام الدين أسلم الحنفي(ت 802هـــ/ 1399م) خصوصية عنده (ابن تغري بردي، 1971 : ص236 237) كما كان الفقيه الحنفي أحمد بن كندغدي من المقربين عنده حتى صـــار يقيم عنده فترات طويلة، أما الفقيه الحنفي أكمل الدين البايرتي فكان برقوق ينتظره حتى ينتهي من دروســــه ليخرج ويركب معه، وكان

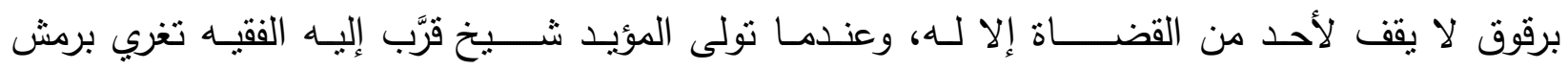

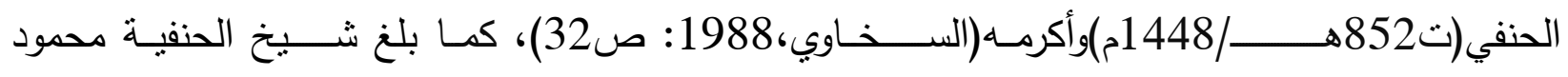
الأقصرائي(ت25825ه/1421م) منزلة مرموقة معظمة لدى المؤيد شيخ (السخاوي، 1997: صائ528-529). 
كما تحيز الســلطان الظاهر ططر للمذهب الحنفي (ابن تغري بردي،1988: صـ405)، حتى نال مشايخه مكانة معتبرة عنده، ومنهم : الثيخ شمس الدين محمد بن حسن ، الذي كان حظيا عنده طوال فترة حكمه (ابن تغري بردي، 1992: ص233- 234)، وفي إطار الاهتمام بالأحناف وتمييزهم أعطى السلطان الظاهر ططر لأحد الفقهاء الأحناف عشرة آلاف دينار وأوقف له زاوية.

أما السلطان خشقدم(تولى الحكم سنة 865هـ/ 1460م حنى 872هـ/1467م) فكان معظمًا للمؤرخ الحنفي ابن تغري بردي(ت1815هـ/1412م)، الذي كان كلامه مقبولا وحوائجه مقضية عند السلطان(ابن تغري بردي، 1992: ص233- 234) ، وكذلك أجلَّ خثقدم الثيخ أمين الأقصرآي(ت 880هـ/ 1475م) حنى أنه أرسل إليه يستشيره فيمن يصلُح لقضاء الثافعية(السخاوي، 1992: ص242) كما كان السلطان قايتباي(ولي الحكم سنة 872هـ/1467م حتى سنة 901هـ/1495م) يتودد للآقصرآي ويتواضع له على الرغم من شدة هجومه

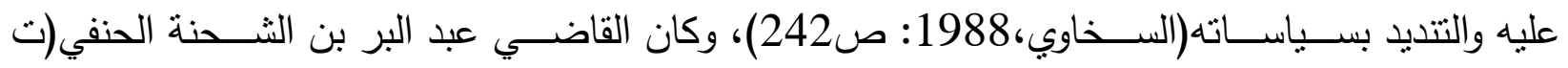
921هــ/1515م) من المقربين للسلطان الغوري(ابن العماد الحنبلي، 1986: ص162،159)؛ حيث كان يقيم بالقلعة ثلاث ليال في الأسبوع، كما صـار هو المقرر في أمور الدولة مع السـلطان(ابن إياس، 1983: ص470) كذللك أصـبح لعلماء الأحناف مكانة عند الأمير محمد بن السـلطان جقمق (السـخاوى،2005: ص191)، الذي قرَّب غير واحد منهم كقاضي القضاة سعد الدين الديري(867هـ/1462م)، والعلاهة محيي الدين الكافيجي(ت 879هـ/1474م)، والعلامة قاسم الحنفي(ت 879هـ/1474م)، والأخيران كانا يلازمانه في غالب الأوقات ليلًا ونهارًا(ابن تغري بردي، 1992: ص236) وبالمثل كانت للفقيه الحنفي تغري برمش التركماني منزلة عند كثيرٍ من الأمراء وله محبةٌ وتعظيمٌ(ابن تغري بردي، 1988 : ص56 - 57).

أهلت المكانة التي وصـل إليها الأحناف في الدولة المملوكية أمراءهم وقضــاتهم وفقهاءهم أن يتولوا كثيرًا من وظائف الدولة، فكان لبعضـهم وظائف عسكرية، كما عُين منهم قضــاة ومفتون ومحتسـبون ونظار وولاة لبيت المال، فضلا عمن نولى منهم بعض الوظائف الديوانية. 
ظل المماليك في مصر يسيرون على النهج الذي بدأه السلطان بييرس في تعيين قاض لقضاة الحنفية (ابن دقماق، 1982: ص275)، وتعيين نواب له لمعاونته في الأحكام الثـرعية(د. حسن البطاوي، 2007: ص63) وأُسـندت للأحناف في العصـر المملوكي ولاية الفصـل في قضـايا الجند من قتل وسـرقة وعصـيان للأوامر وتدبير للتثرات الداخلية، وقد تولوها مع قضـاة الثـافعية والمالكية، وعُرف كل واحد من هؤلاء القضـاة الثلاثة بـــــقاضـــي العـــكر"(محمد البقلي، 1983: ص265) كما عيَّن ســـلاطين المماليك مفتين من الأحناف (ابن كنان، 1991: ص143).

بلغ عدد قضاة القضـاة الأحناف في مصر خلال عصر سـاطين المماليك أربعين قاضيًا في إحدى وخمسين ولاية، إذ نكررت ولاية تسعة قضاة لهذه الوظيفة أكثر من مرة كبدر الدين العيني(ت 855هـ/1451م)، الذي نكررت ولايته لقضاء الأحناف، إذ تولاه سنة 829هـ/ 1425م(ابن حجر، 1988: ص432) وعزل سنة 833هـ/ 1429م، ثم تولاه سنة 835هـ/1431م وعزل عنه سنة 842هـ/1438م(ابن تغري بردي، 1992: ص288،286، وقد، زاد متوســـ فترة ولاية القاضــي منهم للوظيفة عن خمســة أعوام، وبالنظر إلى نهاية ولايات القضاة، نجد أن عدد القضاة الذين انتهت ولايتهم للوظيفة بالعزل تشاوى مع عدد القضاة الذين انتهت ولايتهم للوظيفة بالوفاة، بالإضــافة إلى أن كثرة العزل للقضــاة الحنفية لم تحدث إلا في فترات الفتن الداخلية بين أمراء المماليك، وهو ما يعني أن وضع قضاة القضاة الأحناف كان أكثر استقرارًا إذا قورن بقضاة القضاة

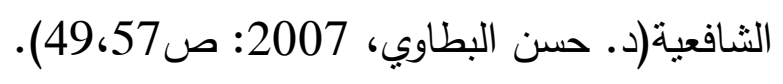

تعددت الطرق التي اختير بها قاضـي قضـاة الحنفية في العصر المملوكي، فقد كان يختاره السلطان أو أحد الأمراء من ذوي السـلطة والنفوذ، وكان المختار غالبا على علاقة بالسـلطان أو أحد الأمراء؛ فقد ولي القاضي حسام الدين الرازي (ت699هـ/1299م) قضاء الحنفية بعد تولي السلطان حسام الدين لاجين الحكم سنة 696هـ/1297م، وكان صديقًا للسلطان، كما ولي شمس الدين الطرابلسي( ت799هـ/1396م) قضاء 
قضاة الحنفية سنة 786هـ/ 1384م لصداقته مع كاتب السر أوحد الدين(786هـ/ 1384م) ، رغم وجود من هو أعلم منه من علماء الحنفية(ابن الصيرفي، 1971: ص95). وأصبح ناصر الدين ابن العديم (ت819هـ| 1416م) قاضي قضاة الحنفية سنة 811هـــ/ 1408م بوساطة الأمير تغري بردي الأتابكي(ت 815هــــ 1412م) لأنه كان متزوجًا من إحدى بناته(ابن تغري بردي، 1988: ص124)، وشـاور بعض الســلاطين أحيانًا قضـاة المذاهب الثناثة الأخرى في اختيار من يصـلح لتلك الوظيفة من الأحناف (د. حسـن البطاوي، 2007 : ص49)؛ ففي رجب من سـنة 782هـــ/ 1380م اسـتدعى الأمير الكبير برقوق قضــاة القضـاة الثـافعية والمالكية والحنبلية، وشـاورهم فيمن يصـلح لوظيفة قاضـي قضــاة الحنفية، فأثـار برهان الدين بن جماعة الثافعي بولاية صدر الدين الدمشقي(ت 786هــ/1384م) ، فأرسلوا إلى دمشق لإحضاره(المقريزي،

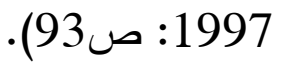
كما لعبت الوراثة دورًا مهمًا في اختيار قاضـي قضـاة الحنفية في العصـر المملوكي، فعندما أثـرف كمال الدين ابن العديم قاضـي قضـاة الحنفية على الموت، أوصى ابنه ناصـر الدين ألا يترك وظيفة قاضي القضاة، فلم يدع ابنه وسيلة إلا اتخذها للوصول إلى المنصب(ابن الصيرفي، 1971: ص374)، ومن الأسر التي توارثت تلك الوظيفة أسـرة علاء الدين التركماني(ت 750هـــ/1349م) التي وليت وظيفة قاضـي قضـاة الحنفية من سـنة 748هـــ/1347م حتى وفاة صـدر الدين التركماني (ت776هـــ/1375م) باسـتثناءات قلبلة(د.حسـن البطاوي، 2007: ص48)، كما اثـتهرت أيضًّا أسـرة ابن الديري، وأسـرة ابن الثـحنة بتولي قضاء الحنفية في مصر (د.حسن البطاوي، 2007: ص58).

تدخل مشـايخ الأحناف أحيانًا لفرض من يرون فيه كفاءة علمية لنشغل منصب قاضـي قضـاتهم؛ فقد اجتمع رأي كثير من فقهاء الحنفية سنة 750هـــ/ 1349م على أن يكون قاضيهم هو جمال الدين عبد الله (ت769هـ/1368م) ابن قاضي القضاة علاء الدين التركماني بعد وفاة والده وخلو المنصب، وطلبوا ذلك من الأمير شيخون العمري(758هـ/1356م) وغيره؛ فأجييوا إلى ذلك، واستقر جمال الدين في القضاء وعمره دون الثلاثين(المقريزي، 1997: ص101)، كما فرضـــ الثـــهرة العلمية لبعض الأحناف، وما عرف عنهم من 
النزاهة والعفة، أحيانًا، اختيار أصــابها لمنصـب قاضــي القضــاة؛ فقد كان لثــرة جمال الدين الملطي(ت ات 803هـ/1400م) وعلمه أثز في اختباره حتى خرج البريد بطلبه من الثنام سنة 800هـ/ 1397م لولاية قضاء الحنفية في مصر بعد أن ظل المنصب شاغرًا مائة وأحد عشر يومًا، فحضر إلى القاهرة، وظل في المنصب حتى وفاته (ابن تغري بردي، 1992: صبر بـ 123).

كان للبذل والبرطلة أيضـا دور في حصـول بعض الأحناف على منصـب قاضـي القضــاة؛ فحسـام الدين بن الثـــنة تولى قضــاء الحنفية مقابل ثلاثة آلاف دينار (ابن إياس، 1983: صـ477)، أما ناصــر

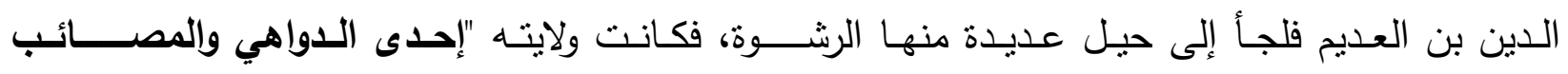
العظام"(المقريزي،1997: ص110)، وهو ما ألحق الضرر بالمذهب الحنفي وسمعته(ابن الصبرفي، 1971: ص374)، وبالمثل أسـاء بعض قضاة القضاة الأحناف السيرة ، فحسام الدين الغوري الذي استقر في قضاء الحنفية سنة 738هـ/ 1338م، ساءت سيرته، واثتهر بالبذاءة، وكان قليل المعرفة، يُعاقب بالضرب الثنديد، ويبالغ في ذللك(ابن حجر، 1993: ص14-42)، والأنكى من ذلك أنه ضُبط وهو يتتاول الحشيش(المقريزي، 1997: ص253-354). كذللك لم يكن جمال الدين الملطي محمود السـيرة؛ فقد قرب الفــاق، وكان يفتي بأكل الحشـــش، ووجوه من الحيل في أكل الربا، ويمنع الناس من النظر في صــــحيح البخاري، وقد هجاه القاضـي محب الدين ابن الثــنة (ت1890هـــ1485م) فكثـف عن سـوء سـيرته (السـخاوي، 1966: ص409).

في المقابل، رفض بعض مشايخ الحنفية وفقهاؤهم تولي وظيفة قاضي القضـاة في العصر المملوكي تورعا وهيبة لمسـؤوليتها، خاصــة أنه قد ورد عن الرسـول (صـلى الله عليه وســلم) أحاديث تُحذر من ولاية القضاء، وإن لم يكن من المستبعد أن رفض بعضهم كان بسبب ما يترتب على القبول من ضرورة الانصياع لأوامر السلاطين والأمراء(سماح بنت سعيد، 2010: ص149)، فجال الدين التباني(ت793هـــ/1390م) أخرج مصـــفًا للسـلطان الظاهر برقوق واســتحلفه بـه أن يعتقه من أمر ولاية القضــاء(ابن إياس: 1983، ص276)، كما امتتع أبو العباس أحمد(ت 872هـ/1467م) عن قبول تولي قضاء الحنفية(السيوطي، 1967 
: ص475)، أما سـعد الدين الديري الذي ترأس السـادة الحنفية في زمانه فرفض ولاية قضـائهم، ولم يقبل إلا بعد إلحاح الأتابك جقمق والسـلطان يوسـف بن برسـباي، وبعد أن شـرط عدة شـروط(ابن حجر، 1988:

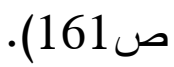

عيَّن قضــاة القضــاة الأحناف في العصـر المملوكي نوابهم بموافقة السـلطان، ولم يكن مسـوحًا لهم بذللك حتى أوائل حكم المماليك؛ لأن قاضـي القضـاة الثـافعي هو من كان بعينهم جميعًا، فلما عُين القضــاة الأربعة أصبح لكل قاضي قضاة أن يعين نوابه وفق مذهبه(د. عبد المنعم ماجد، 1967م: ص99)، وقد بالغ بعض قضاة القضاة الأحناف في استتابة نواب عنهم، فضيَّق عليهر سـلاطين المماليك، ويذكر ابن إياس أن السلطان المؤيد شيخ رسم سنة 818هـــ1415م لقاضي القضاة ناصر الدين ابن العديم بستة نواب فقط، واثـــترط عليه شـــروطًا كثيرة بعد أن أنكر عليه كثرة نوابه(ابن إياس، 1983: ص19-20)، وإمعانًا في التضييق أصدر سنة 819هــ/ 1416م قرارًا بعزل نوابه جميعًا، وبعد الوساطة أذن بأن يكون له من النواب ثمانية(ابن إياس، 1983 : ص26)، ثم زاد عدد النواب في عهد السـطان الأشـرف برسباي( ت841هــــ/ 1437م) سـنة 835هـــ/ 1431م إلى عثرة نواب(ابن تغري بردي، 1992: ص194-195)، ثم وصل عددهم في عهد السلطان الغوري إلى ثلاثين نائبًا، ولم يبد السلطان اعتراضًا (ابن إياس، 1983: ص252)،

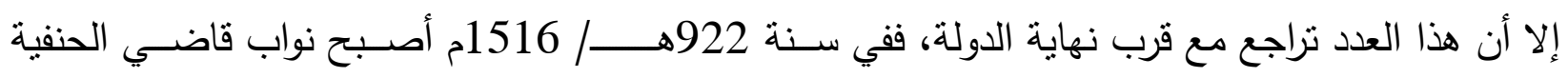

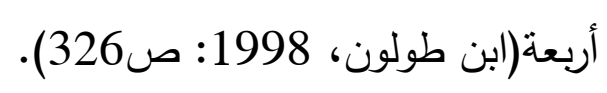

قام بعض نواب الحكم الأحناف بمهام وظيفتهم، وأحسـنوا السـيرة، ومنهم القاضـي ابن الفرات(الغزي، 1970: ص325) وكان فقيهًا محدثًا، بانشر نبابة الحكم(الغزي، 1970: ص325)، والقاضي تاج الدين ابن نصر الهذ(ت 820هـ/1417م) الذي تولى العديد من الوظائف، وكان أحد نواب الحكم الحنفية المعتبرين(ابن تغري بردي، 1992: ص286)، وفي المقابل أسـاء بعض نواب الحكم الأحناف إلى المذهب خاصــة، وإلى القضاء عامة، بما عرف عنهم من سوء السيرة، ومنهم ناصر الدين النبراوي الذي كان مدمنًا للخمر، مطعونًا عليه في شـهادته، وقد وصـل إلى نيابة الحكم بسـبب صـلته بأحد الأمراء(البقاعي، 1992:ص47)، وقد 
تعرض بعض نواب الحكم الأحناف للسجن على يد سلاطين المماليك، فالسلطان الظاهر جقمق، سجن بعض نواب الحكم الأحناف، ومنهم: القاضي بدر الدين العيني، والقاضي قوام الدين العجمي، وقاضي بولاق شهاب الدين قرقماص، وكان سبب ذللك هو تسرع السلطان في أحكامه وقبوله بكلام حاشيته، إذ كان لا يتروى في أحكامه حتى يأتيه من يخبره بالحق(ابن تغري بردي، 1988: ص296-297).

عيَّن سلاطين المماليك قضاة للعسكر من الأحناف، فجلسوا بدار العدل عند جلوس السلطان للنظر في المظالم، فإذا رُفع للســطان قضـايا تتعلق بالعسـكر ، تحدث معهم فيها (ابن فضـلـ الله العمري، 1988: ص161)، وقد تولى هذه الوظيفة من الأحناف صــدر الدين أبو الربيع، والنعمان الحطيني، وعبد الوهاب

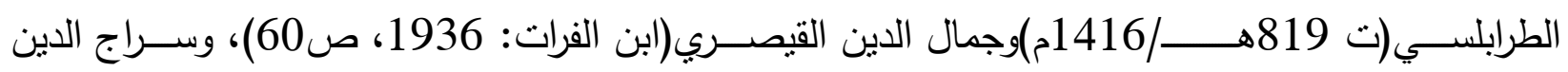

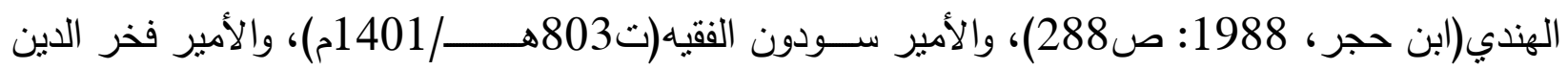

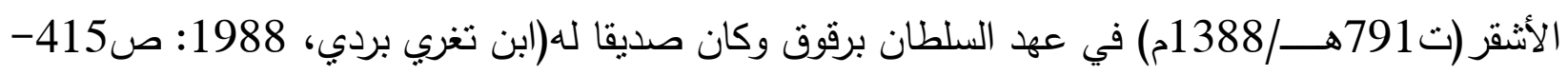
416)، وكان شمس الدين بن الصائغ (ت 776هـــ/1374م) أشهـر من تولى هذه الوظيفة من الأحناف في لي

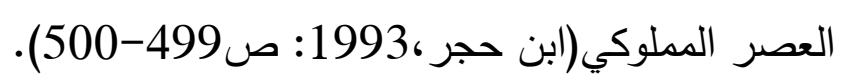

كما عيَّن ســـاطين المماليك كذللك مفتين من الأحنـاف(ابن كنان، 1991: ص143)، وجلس المفتون بدار العدل للنظر في المظالم والفتيا فيها، وممن ولي الإفتاء من الأحناف في مصـر خلال العصـر المملوكي شـــمس الدين ابن الصــــائغ، وركن الدين القرمي، وتقي الدين الجيتي، وزين الدين التقهني(ت $\cdot(1445 / 849$

ثالثا: المحتسبون والنظار الأحناف:

لم يكن في مصـر كلها قبل العصـر المملوكي إلا محتسـب واحد له الحق في تعيين نواب عنه في أنحاء البلاد(القلقتـندي، 1922: ص487)، أما في العصــر المملوكي فتعدد المحتسـبون، إذ كان للقاهرة محتسب يتصرف في أمور حسبتها، وله نواب في الوجه البحري، وللفسطاط محتسب وله أن ينيب عنه في 
الوجه القبلي، ولما أصبحت الإسكندرية ولاية خاصة سنة 767هــ/ 1365م خصص لها محتسب، لم يتعد اختصـاصـه المدينة وظواهرها (د. سـهام أبو زيد، القاهرة 1986: ص88)؛، وقد اختير محتسبو مصر خلال العصر المملوكي من بين أصحاب المذاهب، فتتافسوا فيما بينهم على الوظيفة، وكان ممن تتافس عليها من الأحناف بدر الدين العيني(المقريزي: 1997، ص457).

اشتهر من محتسبي الأحناف في مصر خلال عصر المماليك صدر الدين العجمي(ت 833هـــ| 1429م)، وتولاها عدة مرات، في سنوات 815هـ/1412م، و822هـ/ 1419م، و824هـ/1421م(د. سهام أبو زيد، 1986: ص268-269)، وفي كل مرة قُوبل تعيينه بفرحة من العامـة نظرًا لمعرفته وعفته (ابن حجر، 1994: ص191، 238). ومن الأحناف الذين تولوا الحسـبة في مصـر في العصـر المملوكي بدر الدين العيني، وقد تولاها عدة مرات كذلك، كان أولها سنة 801هـ/1398م وعُزل في السنة نفسها، ثم تولاها مرات أخرى سنوات 803هـ/ 1400م، و819هـ/ 1416م، و844هـ/1440م، وكان آخرها سنة 847هـ/ 1443م(د.ســـام أبو زيد، 1986: صـ271،2641)، وفي إحداها كان العيني خلفًا لصــدر الدين العجمي،

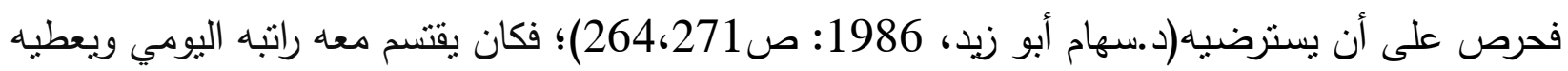
دينارا ويكتفي هو بدينار حيث كان يتقاضى دينارين في اليوم (ابن حجر، 1994: ص275).

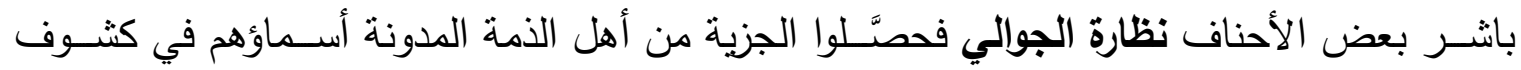
وسـجلات(د.محمد أمين، 2006:ص1286)، وصـرفوها على العلماء والفقراء(ابن كنان، 1991: ص160)،

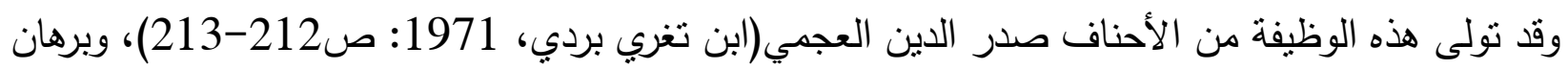
الدين الديري(ت876هـ/1471م)، وأمين الآقصرآي(ابن إياس، 1983: صـ107)، كما باشر بعضهم نظارة الأحباس فكانوا مسـؤولين عن أموال الجوامع والمسـاجد والزوايا والمدارس(القلقشـندي، 1983: صـ38)، وقد باثــر هذه الوظيفة بدر الدين العيني في عهد السـلطان المؤيد شــيخ(ابن تغري بردي، 1992: ص287)، وجمع بينها وبين القضـاء والحسبة، ولم يجتمع ذلك لأحد قبله(السـخاوي، 1966: ص434)، وتولاها أيضًا برهـان الـدين الـديري في ســلطنـة الظـاهر جقمق(الســـــاوي، 2005: ص7)، وعلاء الـدين الغزي 
سنة857هـــ1453م(ابن تغري بردي،1990 : ص428)، كما عُين بعضهم ناظرًا للكسوة فاختص بكل ما يتعلق بأمر الكعبة وكسوتها وأوقافها، وما يستعمل فيها من ذهب وحرير (ابن كنان، 1991: ص صن1:161)، ومن

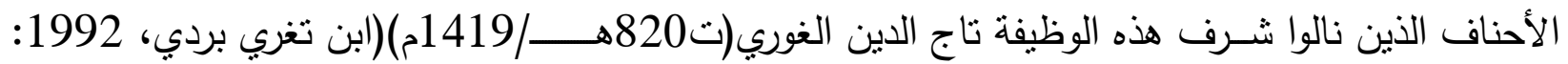
ص286)، وشـرف الدين التباني (ت827هــــ/ 1423م) الذي كان وكيلا لبيت المال بمصـر منذ ســـة 815هـ/1412م وحتى وفاته سنة 827هـ/ 1423م(ابن حجر، 1994: صب04-89-90).

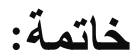

تتاولت الاراســة مكانة الأحناف في الاولة المملوكية ، والقضــاة والمفتون الأحناف، والمحتسـبون وإلنظار ، وقد تمخضـــت عن عدة نتائج منها: أن مكانة الأحناف في مصــر خلال العصــر المملوكي أصبحت مكانة مرموقة بعد تقسيم القضـاء إلى المذاهب الأربعة، فبات لهم قضـاة ونواب يحضـرون مجالس الثـورى ويحصـلون على امتيازات مختلفة ويأنتون في المرتبة الثانية بعد قضـاة الثـافعية، وقد نال الأحناف رعاية الأمراء والسلاطين الأحناف فوصلوهم وقربوهم واستشاروهم.

كما اتضـح أيضــا أن أمراء الأحناف في مصـر خلال عصـر المماليك باشــروا كثيرا من الوظائف العســكرية، فمنهم من وصــل إلى مرتبة نائب الســلطان القائم مقامه، ومنهم من تولى نيابة الغيبة، وقيادة الجيش، وولاية بعض الولايات، والإستدارية، ومن ترقى إلى رأس نوبة الجمدارية أو ناب في القلعة.

تبين أيضا أن قضاة القضاة الأحناف في مصر خلال عصر المماليك وصل عدد ولايتهم إلى إحدى وخمســين ولاية، هذا إلى جانب نوابهم الذين تراوح عددهم بين أربعة وعثـرة نواب، بالإضــافة إلى قضـــاة العسكر ، مما يعني زيادة عدد قضـاة الأحناف في هذا العصر زيادة كبيرة عن غيره من العصور ، وأن هؤلاء القضاة سيطروا على كثير من مفاصل الدولة المملوكية، وقد تتوعت طرق اختيار قاضي قضاتهم، فتمت عن طريق العلاقات الودية مع السلاطين أحيانًا، أو عن طريق البذل والبرطلة أحيانا أخرى. 
خلصت الدراسـة إلى أن وظائف الأحناف في الدولة المملوكية بمصر لم تقتصر على القضـاء، فقد تولى كثيرون منهم الحسبة، كما باشر بعضهم نظارة بعض الأعمال في الدولة كالجوالي والأحباس والكسوة، وكان صدر الدين العجمي وبدر الدين العيني أثهر محنسبي الأحناف في الدولة المملوكية.

\section{المصادر والمراجيع}

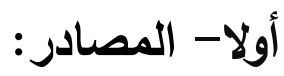

1- ابن إياس: (محمد بن أحمد بن إياس المصري، ت930هـــ1510): بدائع الزهور فى وقائع الدهور : تحقيق: محمد مصطفى زياده،الهيئة المصرية العامة للكتاب - القاهرة 1983.

2- ابن الأخوة: (محمد بن محمد بن أحمد القرشى، ت 729هـــ/1329م):معالم القربة فى أحكام الحسبة (تحقيق: محمد محمود شعبان - صديق المطيعي، الهيئة المصرية العامة للكتاب، القاهرة 1976م) 3- ابن بطوطة: (شمس الدين أبى عبداله محمد بن عبداله الطنجى، ت 779هـ/1377م): تحفة النظار فى غرائب الأمصار وعجائب الأسفار (تحقيق: عبد الهادى التازي، أكاديمية المملكة المغربية، الرباط 1997م) 4- البقاعي: (إبراهيم بن عمر البقاعى، ت 885هـ/1480م): إظهار العصر لأسرار أهل العصر، تحقيق: محمد سالم العوفي - د.م 1992م. 5- ابن تغري بردي: (جمال الدين أبو المحاسن يوسف، ت 874هـ/1469م):النجوم الزاهرة فى ملوك مصر والقاهرة، تحقيق: محمد حسين شمس الدين، دار الكتب العلمية بيروت 1992.

6- ..................

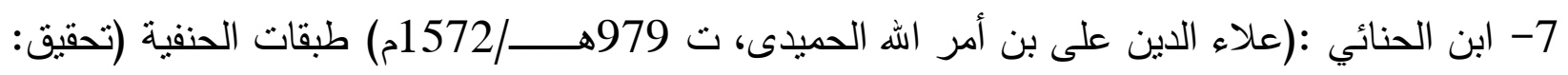
محى هلد، مطبعة ديوان الوقف السنى، بغداد 2005) ج3، ص50. 
8- ابن حجر العسقلانى: (شهاب الدين أحمد بن محمد، ت852هـ/1482): رفع الاصر عن قضاة مصر , تحقيق: على محمد عمر، ط1، مكتبة الخانجى- القاهرة 1988.

9-.................. 9

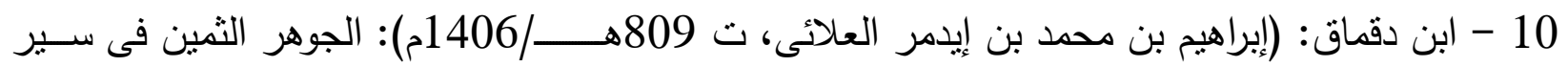
الخلفاء والملوك والسلاطين، تحقيق: سعيد عاشور، جامعة أم القرى- مكة 1982. 11- السخخاوي: (محمد بن عبد الرحمن بن محمد، ت902هـــ/1496م) التبر المسبوك فى ذيل السلوك، ج3، تحقيق: لبيبة إبراهيم- نجوى مصطفى، دار الكتب المصرية، القاهرة 2005م. 12- ----- الذيل على رفع الأصـر ، تحقيق: جودة هلال ومحمد صـبيح، مراجعة: علي البجاوى، الدار المصرية للتأليف، القاهرة 1966.

13 -------- الضوء اللامع فى أعبان القرن التاسع ، دار الجيل - بيروت 1992. 14- السيوطى: (جلال الدين عبد الرحمن بن أبي بكر ت911هـــ/1505م): نظم العقيان ، حرره:فيليب حتى، المكتبة العلمية - بيروت 1927.

15----- حسن المحاضرة فى تاريخ مصر والقاهرة ، تحقيق: محمد ابو الفضل إبراهيم - د.م1967. 16--------بغية الوعاة (تحقيق: محمد أبو الفضل إبراهيم، المكتبة العصرية، بيروت د.ت)

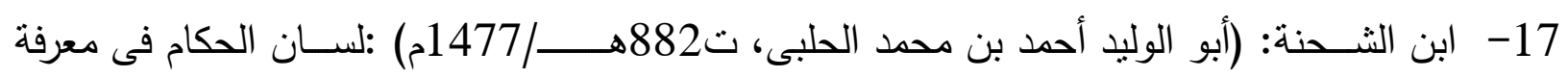
الأحكام،تحقيق:طه عبد الرؤوف، المكتبة الأزهرية للتراث - القاهرة 2013

18- الثوكاني: (محمد بن على بن محمد، ت1250هـــ/1834م): نيل الأوطار، ج8، تحقيق: عصـام الدين الصبابطي، دار الحديث - القاهرة 1993م. 
19- الصفدي : أعيان العصر وأعوان العصر، تحقيق: علي أبو زيد وآخرون، دار الفكر - دمشق 1998. 20- ابن الصيرفي: (علي بن داود، ت900هـــ/1494م): نزهة النفوس والأبدان، ج 2، تحقيق: حسن حبش، دار الكتب المصرية- القاهرة 1971.

21 - -------- إنباء الهصـر بأبناء العصـر (تحقيق:حسـن حبثـي، الهيئة المصـرية العامة للكتاب،

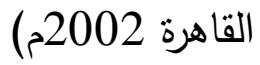

22- ابن طولون: (شمس الدين محمد بن علي، ت953هـ/1546م): مفاكهة الخلان فى حوادث الزمان، تحقيق: خليل المنصور، دار الكتب العلمية- بيروت 1998م.

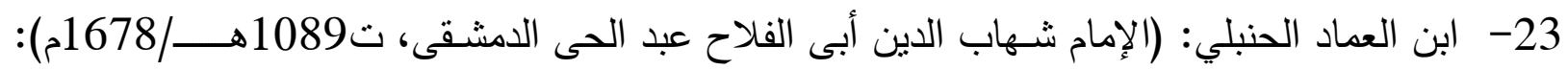
شذرات الذهب فى أخبار من ذهب ، تحقيق: محمود الأرناؤوط،، دار ابن كثير - بيروت 1986م 24- العدرى: (ثـهاب الدين ابن فضل اله ت 749هـــ1348م)التعريف بالمصطلح الثـريف (تحقيق: محمد حسين شمس الدين، دار الكتب العلمية، بيروت1988) 25- ابن الفرات: (ناصر الدين محمد بن عبد الرحيم، ت 807هــ/1405م):تاريخ ابن الفرات مج9،ج1، تحقيق: قسطنطين رزيق، المطبعة الأميركانية - بيروت 1936.

26- الفيروزآبادى: (مجد الدين محمد بن يعقوب، ت 817هـــ/1414م):القاموس المحيط (مكتبة تحقيق التراث، مؤسسة الرسالة، ط8، بيروت 2005م

27- القرشي: (محى الدين أبى محمد عبد القادر القرشى الحنفى، ت 775هـ/1373م) :الجواهر المضية فى طبقات الحنفية، تحقيق:عبد الفتاح الحلو، ط2، دار هجر - الجيزه 1993م. 
28- القلقتـندى : (أبو العباس شهاب الدين أحمد بن على، ت 821هـــ/1418م): صبح الأعثى فى صناعة الأنثا، ج4، دار الكتب المصرية - القاهرة 1922.

29- ابن كثير : (عماد الدين أبى الفداء إسماعيل القرشى، ت 774هـ/1372م):البداية والنهاية ، تحقيق: عبداله بن عبد المحسن التركى، دار هجر - الجيزة 1998.

30- ابن كنان: (محمد بن عيسى، ت 1153هـــ/1740م): حدائق الياسـمين فى ذكر قوانين الخلفاء والسلاطين، تحقيق: عباس صباغ، دار النفائس، بيروت 1991م.

31- اللكنوي: (محمد عبد الحي بن محمد أبو الحسنات، ت1304هــ/1886م): الفوائد البهية فى تراجم الحنفية، تحقيق: محمد بدر الدين النعسانى، مطبعة السعادة- القاهرة 1324هـ/1906م.

32- الماوردي: (أبو الحسن علي بن محمد بن حبيب، ت450هـــ/1058م) الأحكام السلطانية والولايات الدينية (تحقيق: أحمد مبارك، دار ابن قتيبة، الكويت 1989م) ص315.

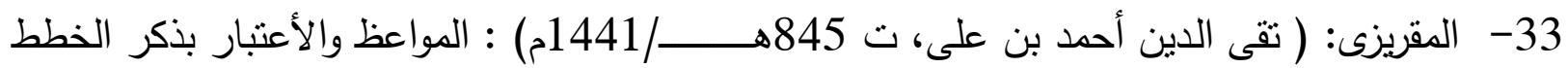
والاثار، تحقيق: أيمن فؤاد سيد، مؤسسة الفرقان للتراث الإسلامي، لندن 2004.

34- ------- الســلوك لمعرفة دول الملوك, تحقيق: محمد عبد القادر عطا، دار الكتب العلمية -

$$
\text { بيروت 1997م }
$$

35- ابن نجيم الحنفي: (زين العابدين بن إبراهيم بن محمد، ت970هـ/1562م) : الرسائل الزينية(تحقيق:

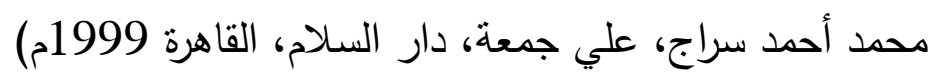

36- النسائى: (أبو عبد الرحمن أحمد بن شعيب، ت 303هـ/915م):السنن الكبرى (حققه وأخرج أحاديثه: حسن عبد المنعم شلبي، مؤسسة الرسالة، بيروت 2001) ج5، ص398 
37- النعيمى:(عبد القادر بن محمد الدشقى، ت978هـــ1570م) : الدارس في تاريخ المدارس، ج 1،

$$
\text { دار الكتب العلمية - بيروت } 1990 .
$$

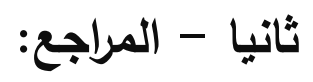

1- د. أحمد عبد الرازق: البذل والبرطلة (الهيئة الهصرية العامة للكتاب، القاهرة 1979م)

2- د.حسـن البطاوي: أهل العمامة في مصـر عصر سـلاطين المماليك، عين للدراسـات والبحوث - الجيزة .2007

3- د.سعيد عبد الفتاح عاشور : العصر المماليكي فى مصر والثام، دار النهضة العربية - القاهرة 1965 4-----المجتمع المصري في العصر المملوكي، دار النهضة العربية - القاهرة 1992م. 5 - د.قاسم عبده قاسم : عصر سلاطين المماليك(التاريخ السياسى والاجتماعى)،عين للاراسات والبحوث الجيزه 1998.

6 - د. عبد المنعم ماجد: نظم دولة سلاطين المماليك(القاهرة 1967م) • 7- محمد الثشتاوي: ميادين القاهرة (دار الآفاق العربية، القاهرة 1999م). 8- د.محمد أمين: الأوقاف(دار النهضة العربية، القاهرة 1980م). 9- محمد البقلي: التعريف بمصطلحات صبح الأعثى (الهيئة المصرية العامة للكتاب، القاهرة 1983م

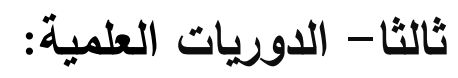
1- جابر سلامة: قاضي القضاة فى مصر على عصر الأيوبيين والمماليك، مجلة كلية الآداب - جامعة الاسكندرية 1983. 
2- د.ليلى عبد الجواد: ظاهرة تعاطي الحشـــش ومكافحتها (مجلة المؤرخ العربي، القاهرة، العدد 16، مارس 2008م).

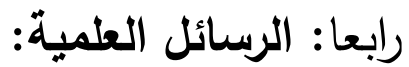

1- حماده محمد حســين: المذاهب والفرق الدينية(رســـالة ماجســتير، كلية دار العلوم، جامعة المنيا $($ 2006 2- خالد الحريري: قاضـي القضـاة ودوره في دولة المماليك البحرية، رسـالة ماجستير غير منشـوره، كلية الآداب - جامعة دمشق 2012م.

3 - ســاح بنت سـعيد: الأثر السـياسـي والدور الإصــلاحى للعلماء فى مصـر فى عصـر سـلاطين المماليك، رسالة ماجستير غير منشوره ، كلية الثريعة والدراسات الإسلامية - جامعة أم القرى، مكة 2010.

The Religious Functions of the Hanafis in Egypt in the Mamluk Era (648-923 AH / 1250-1517 CE(

Muhammad Muhammed Maghawri Muhammad 
العست المجالهيه - الجزء الأول(2021)

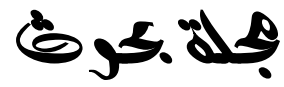

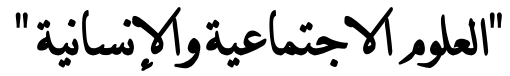

Research Affairs and Student Education Specialist

Faculty of womens - Ain Shams University

Supervisied by

Amal Muhammad Hassan

Assistant Professor of Islamic History- Faculty of womens, Ain Shams University

Safa Ali Muhammad

teacher of Islamic history - Faculty of womens, Ain Shams University

Sherine Shalaby Al-Ashmawi

teacher of Islamic history - Faculty of womens, Ain Shams University

\section{Abstract:}

This research aims to monitor the religious functions that the Hanafis assumed in Egypt in the era of the Mamluk Sultans, because this would highlight the position the Hanafis reached in this era, and to reveal the role they played in Egypt during the Mamluk era, and to reflect the image of sectarian activity in this era.

The research dealt with the functions of the Hanafis in the Mamluk state in Egypt, the most important of which was the judiciary, as the Hanafite judges controlled many of the joints of the Mamluk state..

These jobs were not limited to the judiciary, but included the calculation. Some of them also undertook the fieldwork for some work in the state, such as the jawali, the habas, and the keswa.

Key words: the Hanafis - jobs - Judges 